Motrivivência Ano XXIII, No 37, P. 123-133 Dez./2011

http://dx.doi.org/10.5007/2175-8042.2011v23n37p123

\title{
O HOMEM NA SOCIEDADE DAS DOENÇAS OU AS DOENÇAS NA SOCIEDADE DO HOMEM? QUAL O PAPEL DA EDUCAÇÃO FÍSICA NESTE ASPECTO?
}

\author{
Ricardo William Muotri \\ Antonio Carlos Simões²
}

RESUMO

O estudo teve por objetivo principal responder as perguntas: 1. O homem está ficando mais doente por uma seleção, "de imposição natural"? 2. Ou a sociedade em que vivemos está doente, pela perda de valores morais e éticos, que leva ao homem um desequilíbrio orgânico? Visando despertar o profissional de educação física para sua responsabilidade social como professor. O critério adotado para a pesquisa foi à busca de artigos realizada de forma sistemática nas bases de dados Medline, Scielo, Sportdiscus e Lilacs sem limite de data. Em todos os casos, foram utilizados os termos: educação, ética, valores humanos, educação física escolar e sociedade, de forma combinada em citações no título ou no resumo. Fica claro no texto que vivemos em uma sociedade doente, o que interfere no homem, não só em seu estado físico, mas cognitivo e adaptativo. Desta forma concluímos que a função de educadores vem se tornando cada vez mais responsável pela plenitude cultural de toda uma sociedade.

Palavras-Chave: Educação; Ética; Valores Humanos; Sociedade

\section{Introdução}

O homem, diferentemente de qualquer outro animal, não se sujeita as pressões do ambiente: ele o modifica de acordo com suas necessidades.

De fato o ambiente atual da vida humana é muito diferente daquele em que se processou a 
maior parte da história evolucionária da espécie. (CARVALHO, 1989).

Nos últimos dez mil anos, desde o surgimento da agricultura, o modo de vida da espécie alterou-se de forma acelerada, muito mais rápida do que a evolução biológica seria capaz de acompanhar. Neste período ocorrem, por exemplo, o surgimento da propriedade, a vida urbana, o modo de produção industrial, dos quais por sua vez resultam numa série de transformações nas relações interpessoais, da família e de outros grupos sociais. Que implicações têm esses fatos sobre a possibilidade de uma perspectiva etológica do comportamento humano?

A primeira implicação é que o comportamento humano não deve ser analisado apenas a luz das características do ambiente humano atual, porque este não representa necessariamente o "ambiente natural" humano. O ambiente no qual se processou a maior parte da evolução humana e a definição das características básicas da espécie caracterizáva-se, tanto quanto se sabe atualmente, por um modo de vida de caça e coleta. Isso significa que pode ser necessário considerar as exigências adaptativas desse modo de vida para compreender aspectos de comportamento humano. (CARVALHO, 1989).

Assim segundo ADES 1986, o comportamento social e a sociabilidade são "fenômenos ecologicamente relevantes" no caso da espécie humana.

Hinde, 1987, afirma que embora o dado imediato para o estudo do comportamento social seja o comportamento individual, ao nível do recorte para análise é preciso ultrapassar o indivíduo. $\mathrm{O}$ homem é um ser de vínculos.

Desde a sua concepção, ocorre a inserção do indivíduo humano em uma rede de relações interpessoais, que por sua vez vai construir um grupo social e sucessivamente unidades sociais maiores e mais complexas, é uma característica básica da sociabilidade humana. O desenvolvimento a manutenção e a dissolução de "humores", "atitudes", "sentimentos", e assim por diante - que são "percepções" no sentido de estado ou condição, não sensações ou motivos - constituem tanto uma atividade basicamente privada dos seres humanos quanto o "pensamento" humano orientador.

Além disso, as situações que evocam os movimentos expressivos humanos, e o significado atribuído a eles, diferem amplamente entre as culturas e entre indivíduos de uma mesma cultura. (VAN HOOFF, 1972).

Os movimentos expressivos cuja forma básica é semelhante inter-culturalmente, o impacto 
da cultura pode ser visto em três aspectos. Primeiro, a natureza dos fatores aliciadores é muito influenciada pela experiência: o que chamamos de triste ou divertido é influenciado pela cultura em que vivemos. Segundo, a experiência social afeta o grau em que o estado interno é expresso, por exemplo, até que ponto é permitido mostrar raiva ou interesse sexual. $E$, terceiro, os estados emocionais podem eliciar outros estados emocionais (temos raiva de ter medo, ou temos medo da nossa raiva); esses estados emocionais secundários podem ser culturalmente influenciados, e sua expressão pode se superpuser em degraus variáveis à expressão dos estados primários. (HINDE, 1987).

Desta forma vimos que fatores genéticos podem ser afetados de várias maneiras por influências ambientais e especialmente culturais.

Os estereótipos sociais são extremamente importantes; mas é possível que estes sejam caricaturas de propensões biológicas. O conhecimento de nossa natureza deve ser usado para nos ajudar a atingir nossos objetivos e não para defini-los. As propensões individuais influenciam a estrutura sócio-cultural, mas não a determinam por si mesmas. Todas as diferenças culturais podem estar relacionadas com fatores ambientais, que atuam sobre a natureza das relações através do comportamento dos indivíduos, e sobre essas relações e a estrutura sócio-cultural. As características das estruturas sociais e das estruturas sócio-culturais estão enraizadas nas propensões comportamentais dos indivíduos. (HINDE, 1987).

A cultura humana é gerada, de forma rica e intrincada, por mecanismos de processamento de informação situados na mente humana. Assim fica importante reconhecer que os mecanismos que são adaptações a um modo de vida não são necessariamente adaptativos no mundo moderno, podendo causar um distúrbio iminente momentâneo ou enraizado. (COSMIDES, TOOBY, BARKOW, 1992).

\section{Objetivo e justificativa}

Podemos dizer que nos últimos anos o homem tem se tornado cada vez mais suscetível a alterações patológicas físicas e cognitivas. Isso se deve aos avanços da ciência em detectar e diagnosticar com maior precisão diferentes tipos de doenças ou simplesmente pelo fato de nos submetermos a viver cada vez mais em uma sociedade competitiva e assim o que rege ainda hoje, como nos tempos ancestrais é a adaptação para a sobrevivência.

O homem está ficando mais doente por uma seleção, digamos assim: "de imposição natural"? 
Ou a sociedade em que vivemos está doente, pela perda de valores morais e éticos, que leva ao homem um desequilíbrio orgânico?

Estas são perguntas que nos fazem refletir sobre a capacidade do homem formador de opinião e que possui o poder de transformação social. E pensando neste aspecto incluímos neste estudo a formação profissional e a responsabilidade social do professor de educação física, que atua com crianças, seja em escolas, clubes, academias e nas categorias de base dos esportes. Assim o objetivo principal do estudo visa despertar o profissional de educação física para sua responsabilidade social como professor.

\section{Métodos e procedimentos}

A busca de artigos foi realizada de forma sistemática nas bases de dados Medline, Scielo, Sportdiscus e Lilacs sem limite de data. Em todos os casos, foram utilizados os termos: educação, ética, valores humanos, educação física escolar e sociedade, de forma combinada em citações no título ou no resumo.

\section{Sociedade doente}

Segundo um texto publicado por Durden, 2003: “Uma sociedade doente. Febril. Em estado de coma. Uma sociedade de desigualdades aberrantes. Um mundo de guerras, fome, doenças (sociais ou biológicas). Um mundo onde pessoas desperdiçam toneladas de alimento por ano, enquanto ao seu lado pessoas comem lixo. Uma sociedade em que o pai mata a mãe. Onde a mãe espanca a filha. Uma filha drogada, destruída, viciada em alucinógenos, comprados num quartel general do crime ou induzidos em forma de TV. Irmã de um homem alienado, consumido, destruído pelos tabus, pelos preconceitos, pela indução moral da burguesia esnobe. Corrompido pelo vício, eliminado pelo ralo de um esgoto, se esvaindo em pão, circo e horror. Provando seu machismo com sangue, com masculinidade, com gasolina, fósforo e farrapos humanos. Sendo libertado pelo poder da propina, da influência, do poder pessoal de persuasão. Enquanto somos privados de liberdade pelo estado, pela igreja, pelo patrão. Uma sociedade decadente em seus próprios princípios imutáveis. Princípios velhos, arcaicos, defasados por uma lei da selva. Uma selva de pedra violenta, absurda, subitamente letal em qualquer caminhada descomprometida. É neste mundo que vivemos. Que aceitamos. Que nos tornamos um bando de pessoas frágeis, desorganizadas, infantis, agressivas, manipuladas e arro- 
gantes. E vamos vivendo. Vamos acostumando com esta imundície. Vamos vivendo com contradições, medos, desesperanças, traições. Vida regada de miséria, regada de dúvidas. Regrada, estudada e manipulada. Por pessoas malignas. Que nos usam, que nos vendem, que nos compram por quase nada. Alguns tentam lutar. Fingem lutar, por puro comodismo. Fingem desejar mudanças, mas apenas se escondem em mitos teóricos fálicos, em teorias ultrapassadas, estagnadas por um orgulho revolucionário cancerígeno, que apenas estimula a competição individual. Quando não brigam entre si, ignoram uns aos outros, se enchem de arrogância ao afirmar seus "ismos" com veemência. Falam de seus mártires, de seus teóricos, afirmam-se contrários a idéia de serem manipulados por um governo, um estado, uma classe privilegiada, mas se acorrentam aos seus dinossauros teóricos eternamente. Não ouvem, não escutam, não procuram mediação, apenas auto-afirmação. Buscam uma solidariedade de classe inexistente. Uma classe que não sabe o que é classe. Um povo que não sabe que pode se unir. Apenas se destrói, se corrompe se dividem em times, facções, religiões, associações e grupos de caráter e objetivos diferentes. Objetivos estes, que nos remetem ao único sentimento dominante desta socie- dade: consumir, gastar, dar-se bem à custa do próximo, vencer (mesmo que pisando sobre os demais).

A sociedade do ópio chamado religião, futebol (meio esportivo, sendo este da base ao mais alto desempenho), televisão. Repleta de líderes inúteis, de seguidores e fiéis cegos. Um mundo onde ser negro é ser pobre. Onde ter opções sexuais diferentes é sofrer escárnio, agressão, linchamento seguido de morte. Um mundo anoréxico com seus moldes humanos cheirando a drogas, futilidades e riqueza desfilando em passarelas de neon. Uma completa apatia social. Um mundo de prisões superlotadas, criadouros do crime, viveiros de ladrões, assassinos, facínoras de toda a espécie, vítimas e algozes de um mundo esquizofrênico. É neste mundo insano que criaremos nossos filhos para ver a destruição de animais, de plantas, de seres vivos inocentes, que se transformarão em casacos de pele, em hambúrgueres gordurosos ou apenas diversão momentânea. É neste mundo de caos, poluição e pobreza que observamos a decadência viva, refletida em tudo e em todos. Este é o seu mundo, o nosso mundo e o mundo deles.

E ele se degrada a cada dia que passa. Seja bem vindo a uma sociedade morta. Uma sociedade apática. Feita de exploradores e explorados. Bem vindo à sociedade doente." (DURDEN, 2003). 


\section{Homem doente}

A cultura dispensa o indivíduo de aprender por ensaio, tudo de novo, a cada geração, ao mesmo tempo em que permite a adição de novas aprendizagens decorrentes das experiências de cada um.

Toda evolução requer adaptações anatômicas, fisiológicas e comportamentais. Porém o homem possui a liberdade de alteração comportamental mesmo sob influência do meio ao qual se encontra inserido. $\mathrm{O}$ que muitas vezes isso deixa de acontecer pela fragilidade de comunicação e conhecimento.

A linguagem é, aliás, uma excelente evidência para a ação decisiva de evolução sobre os comportamentos culturais, fato que não tem escapado aos diversos estudiosos do assunto (PASSINGHAN, 1982; FOLEY, 1996).

Concebe-se a estrutura sócio-cultural como produto de cérebros moldados pela seleção e, portanto, ligada a propensões comportamentais, atitudes, medos, e ansiedades dos indivíduos. (EIBL-EIBESFELDT, 1989).

A conclusão é que a atividade de qualquer sistema comportamental é adaptativa para sua sobrevivência, porém valores perdidos de ordem extrínseca modificam a estrutura comportamental do indivíduo não apenas por sua sobrevivência física, mas, sobretudo por sua sobrevivência moral despertando uma liberdade somática das frustrações do indivíduo, ignorando desta maneira o respeito à competitividade cotidiana na sociedade em que se denomina cidadão.

O ser humano é o objeto do próprio sujeito. Um ser humano dotado de consciência, de capacidade de reflexão, do poder de abstração e de uma percepção abrangente da realidade exterior, percepção essa que se mescla com sua característica de inventar e reinventar essa mesma realidade. Por esse motivo, preferimos não considerar um homem um animal racional, ou, pelo menos, não nos apoiamos nesta afirmativa para definir o homem. È fato que usa a razão, mas não, muitas vezes, de uma maneira absolutamente racional. Ou seu sistema límbico faz com que essa razão seja freqüentemente distorcida em função dos sentimentos que acolhe.

O ser humano é muito mais que sua biologia uma vez que é dotado de autoconsciência. Numa definição mais ampla preferimos dizer que "o homem é um ente biográfico" - sua existência não pode nunca ser reduzida no tempo, (o momento presente) e logo no espaço, (a sua biologia); é, na verdade, um somatório de todos os 
momentos "já vividos" do seu futuro em temores, anseios e projetos.

Se a educação física é uma empreitada que visa atender o Homem, não cabe a ela dissecá-lo em vida, separando seu corpo de sua mente ou da sua cultura.

\section{O profissional da Educação}

Atualmente, o jogo, o esporte de alto rendimento envolve grandes somas de dinheiro e neste contexto está em jogo muito mais do que o simples lucro material: o saber, a estima, a honra, a dignidade e o respeito - em suma, o status, (BATESON, MEAD, 1942), fazem parte de todos os princípios perdidos na infância "deseducada", onde trocamos consideravelmente a ambição em sua forma mais honrosa pela ganância em sua forma mais desleal, vindo de uma sociedade doente.

O profissional de educação física pode e deve mudar este jogo. Trabalhando pelo indivíduo na sua educação escolar e primária, principalmente, onde nos dias atuais, a família faz parte cada vez mais adjuvante neste jogo.

O acesso a conhecimentos e habilidades constitui parte do processo de formação humana, mas não deve ser confundido com a totalidade do processo.
Em seu aspecto proposicional, a concepção de que a Educação é o processo integral de formação humana, necessita receber uma nova condição para poder existir no mundo da cultura. Esse processo inclui a aquisição de produtos que fazem parte da herança civilizatória e que concorreram para que os limites da natureza sejam transpostos. Entre eles se colocam os conhecimentos racionais que promoveram o desenvolvimento científico e cultural da humanidade, e a consciência de que o ser humano é o próprio produtor das condições de reprodução de sua vida e das formas sociais de sua organização e devem ser orientadas pelos princípios da solidariedade, do reconhecimento do valor das individualidades, respeito às diferenças, e pela disciplina das vontades. O Ser Humano, por não receber qualquer determinação por natureza, pode construir o seu modo de vida tendo por base a liberdade da vontade, a autonomia para organizar os modos de existência e a responsabilidade pela direção de suas ações essa característica do ser humano constitui o fundamento da formação do sujeito ético.

Para isso, começaremos por examinar se é aceitável, como anunciado com freqüência, que a justificativa mais fundamental para a ação educativa a situa na tarefa prática de preparar os indivíduos para a vida social. 
Podemos reconhecer que a ação educativa é um processo regular desenvolvido em todas as sociedades humanas, que tem por objetivos preparar os indivíduos em crescimento (crianças e adolescentes) para assumirem papéis sociais relacionados à vida coletiva, à reprodução das condições de existência (trabalho), ao comportamento justo na vida pública e ao uso adequado e responsável de conhecimentos e habilidades disponíveis no tempo e nos espaços onde a vida dos indivíduos se realiza.

O exercício de cidadania compreende duas ações interdependentes: a primeira refere-se à participação lúcida dos indivíduos em todos os aspectos da organização e da condução da vida privada e coletiva; e a segunda, à capacidade que estes indivíduos adquirem para operar escolhas. Ambos os aspectos caracterizam o sujeito identificável como cidadão. O exercício da cidadania pressupõe a liberdade, a autonomia e a responsabilidade, fica evidente que se constitui um dever dos cidadãos participarem na organização da vida social. Essa organização deve assegurar a todos o exercício da liberdade e da responsabilidade.

Os cidadãos, munidos dos instrumentos da cidadania, tornam-se construtores de formas organizativas e de ação na vida pública. Essa forma de organização social e de ação política denomina-se Democracia. (Educação \& Sociedade, ano XXII, no 76, Outubro/2001)

O Homem não se define como tal no próprio ato de seu nascimento, pois nasce apenas como criatura biológica que carece se transformar, se recriar como Ser Humano. Esse ser deverá incorporar uma natureza em tudo distinta das outras criaturas. Ao nascer não se encontra equipado nem preparado para orientar-se no processo de sua própria existência. $\mathrm{O}$ ato de formar o ser humano se dá em dois planos distintos e complementares: um de fora para dentro e outro, de dentro para fora.

Nesse sentido, Kant igualmente assegura que a geração mais velha deveria educar a geração mais nova. No entanto, o processo educativo não se reduz a essa formação externa. Ela é necessária, mas não suficiente. Se o fosse, o ato de educar seria um simples exercício de reproduzir o ser humano segundo um modelo externo, o que transformaria o ser humano num objeto a ser trabalhado por um sujeito formador. No segundo plano, educar compreende acionar os meios intelectuais de cada educando para que ele seja capaz de assumir o pleno uso de suas potencialidades físicas, intelectuais e morais para conduzir a continuidade de sua 
própria formação. Esta é uma das condições para que ele se construa como sujeito livre e independente daqueles que o estão gerando como ser humano.

A Educação possibilita a cada indivíduo que adquira a capacidade de auto-conduzir o seu próprio processo formativo.

Ao nascer, todos desconheceram o funcionamento próprio do corpo e, por isso, agimos por reação e segundo os limites e movimentos naturais. É assim que qualquer criança é capaz de se alimentar, ingerir líquidos, expelir excrementos e manifestar desconforto como dor, frio, medo. Não sabe, de início, cuidar do corpo físico e desconhece as necessidades ligadas à higiene, ao descanso, ao manuseio das mãos, e mesmo das potencialidades escondidas na mente e nos sentidos.

Ora, a educação deve abrir tais possibilidades aos indivíduos. Inicialmente, orientamos as crianças a evitar o perigo, a executar atos de higiene, a se alimentar adequadamente, enfim, insistimos no desenvolvimento de hábitos considerados sadios e moderados. O que esperamos? Certamente que as crianças, na medida em que vão se tornando adultas, adquiram autonomia. E quando a terão adquirido? A partir do momento em que puderem dirigir o seu próprio corpo para uma relação saudável consigo mesmo e com o mundo natural. Isto vai levá-la a tomar decisões sobre a própria higiene, alimentação, descanso, preservação da natureza e de relações sociais, operar escolhas em relação ao uso do corpo etc. (Educação \& Sociedade, ano XXII, no 76, Outubro/2001).

As crianças serão enviadas para a Escola cada vez mais cedo e nela permanecerão por um tempo mais extenso. $\mathrm{E}$ isso não será porque há um mundo novo de informações a ser processado e, sim, porque a Escola deverá exercer o tradicional papel das famílias, das comunidades, da religiosidade, e ainda, o que lhe era próprio: desenvolver conhecimentos e habilidades. Ela deverá se ocupar com a formação integral do ser humano e terá como missão suprema a formação do sujeito ético.

\section{Conclusão}

Fica claro no texto que vivemos em uma sociedade doente, o que interfere no homem, não só em seu estado físico, mas cognitivo e adaptativo, levando a uma interferência significativa na transformação de valores éticos para com a sociedade e alterações emocionais somatizadas no indivíduo. Porém os educadores, mesmo fazendo parte desta sociedade enferma devem 
obter conhecimentos necessários a nível universitário para a prática de uma educação mais digna e formadora de indivíduos transformadores e não só adaptativos e egoístas pela sobrevivência sem pudores ou objeções diante das relações humanas.

A função de educadores vem se tornando cada vez mais responsável pela plenitude cultural de toda uma sociedade devastada pelo ódio, pela raiva, pelo egoísmo, pelo desrespeito ao próximo, etc.

Um dos caminhos mais fáceis diante deste processo de formação educadora na sociedade é focado na educação física, principalmente pela facilidade de desenvolvimento social prático através dos esportes, do lúdico, do jogo e das emoções.

\section{Referências}

RODRIGUES, Neidson. Educação: da formação humana à construção do sujeito ético. Educ. Soc. Campinas, v. 22,n. 76,2001.

EIBL-EIBESFELDT, I. Human

Ethology. N.Y.: Aldine de Gruyter, 1989.

FOLEY, R. Humans Before

Humanity. Oxford/Cambridge:

Blackwell Publishers, 1996.

PASSINGHAN, R. The Human

Primate. Osford/SS Francisco:
WH Freeman and Company, 1982.

ADES, C. Uma perspectiva psicoetológica para o estudo do comportamento animal. Boletim de Psicologia, 36, 20-30, 1986. CARVALHO, A. M. A. Etologia e comportamento social. Psicologia e Sociedade. 5 (8), 145-163, 1989.

HINDE, R. A. Individuals, Relationships and culture Links between Ethology and the social sciences. Nova lorque: Cambridge Univ. Press., 1987. COSMIDES, L., TOOBY, J., \& BARKOW, J. H. The adapted mind: Evolutionary Psychology and the generation of culture. Oxford University Press. 1992.

BATESON, G., \& MEAD, M. Balinese Character: A Photographic Analysis. N Y, p.68, 1942.

KANT, I . "Resposta à pergunta: Que é esclarecimento?" Educação \& Sociedade, ano XXII, no 76, Outubro/2001. In: Textos Seletos, Petrópolis: Vozes, 1974. DURDEN, T. (2003) "Sociedade Doente". CMI Brasil - Centro de Mídia Independente. Consultado em 5 de Novembro de 2010, http://www.midiaindependente. org/pt/blue/2003/02/248523. shtml. 


\section{ABSTRACT}

This study aimed to answer the following questions: 1 . The man is getting sick of a selection, "to impose natural"? 2. Or the society we live in is sick, the loss of moral and ethical values, which leads to an imbalance organic man? And thus, aims to attract the professional physical education for their social responsibility as a teacher. The criterion adopted to study and search of answers matching the search the collect was conducted of articles in a systematic manner in the databases Medline, Scielo, Sportdiscus Lilacs and without limit of time. In all cases, the terms were used: education, ethics, human values, education, physical education and society, so combined in quotes in the title or abstract. It is clear in the text that we live in a sick society, which interferes with the man, not only in their physical status, but cognitive and adaptive. Thus concluded that the role of educators, has become increasingly responsible for the fulfillment of a cultural society.

Keywords: Education, Ethics, Human Values, Society.

Recebido em: fevereiro/2011

Aprovado em: março/2012 